\title{
Tomographic Energy Dispersive Diffraction Imaging as a Tool To Profile in Three Dimensions the Distribution and Composition of Metal Oxide Species in Catalyst Bodies**
}

\author{
Andrew M. Beale, Simon D. M. Jacques, Jaap A. Bergwerff, Paul Barnes, and \\ Bert M. Weckhuysen*
}

Metal oxides anchored to a support are widely used as heterogeneous catalysts in a number of important industrial chemical processes. Such heterogeneous catalysts owe their activity to the formation of unique metal-support interactions, which typically result in materials containing highly dispersed metal oxide species stabilized in a particular electronic or coordination state. ${ }^{[1]}$ These catalysts are often employed in fixed-bed reactor processes and, as such, are extruded into millimeter-sized catalyst bodies to minimize pressure drops across the reactor bed. The hydrotreatment of diesel fuels to remove sulfur-, nitrogen-, and metal-containing compounds is one such important catalytic process that utilizes preshaped catalyst bodies. The active phase is proposed to consist of $(\mathrm{Co} / \mathrm{Ni}) \mathrm{MoS}_{2}$ slabs supported on cylindrical $\gamma-\mathrm{Al}_{2} \mathrm{O}_{3}$ extrudates. ${ }^{[2]}$ Recently, owing to increasingly stringent automotive exhaust emission legislation, research has focused on the preparation of more active systems, that is, on new chemical formulations and synthesis methods. Since the efficiency of the final catalytic system depends on both the nature and distribution of the active phase, control of the preparation process is essential, with the final distribution of the active component over the porous support being governed by a combination of physical and chemical processes. ${ }^{[3]}$ A uniform distribution in the entire support can be very difficult to achieve, although it is not always required (e.g. distributions resembling an eggshell, egg white, and egg yolk configuration are sometimes suitable); its necessity depends on the final application. ${ }^{[4]}$

[*] Dr. A. M. Beale, Dr. J. A. Bergwerff, Prof. Dr. B. M. Weckhuysen Inorganic Chemistry and Catalysis Group

Department of Chemistry, Utrecht University

Sorbonnelaan 16, 3854 CA, Utrecht (The Netherlands)

Fax: $(+31)$ 30-251-1027

E-mail: b.m.weckhuysen@uu.nl

Dr. S. D. M. Jacques, Prof. Dr. P. Barnes

Department of Chemistry, University College London

20 Gordon Street, London WC1H OAJ (UK)

and University of London

Birkbeck College, Department of Crystallography

Industrial Materials Group

London WCIE 7HX (UK)

[*** B.M.W. acknowledges financial support by Albemarle Catalysts and the Dutch Science Foundation (NWO-CW-VICl grant). The authors also acknowledge EPSRC/CCLRC for beamtime on station 16.4 and Paul Stukas for technical assistance.

0 Supporting information for this article is available on the WWW under http://www.angewandte.org or from the author.
Recently, different spectroscopic techniques have been developed to obtain spatial information on the distribution of chemical species in catalyst bodies that allow monitoring of the phenomena taking place during their preparation. These techniques include Raman ${ }^{[5]}$ and UV/Vis ${ }^{[6]}$ microspectroscopy as well as magnetic resonance imaging (MRI). ${ }^{[7]}$ The application of these tools provides new opportunities to study, from a fundamental point of view, the physicochemical processes that take place during the preparation of supported catalyst bodies in a time-resolved and spatially resolved manner. Furthermore, they allow for a better control of the dispersion and distribution of the active phase. However, Raman and UV/Vis microspectroscopic techniques yield chemical information in one dimension (1D). The pellets are bisected, and a representation of the sample is selected either judiciously or by performing multiple measurements on different sections of the bodies as a function of time. In contrast, MRI is able to probe in a noninvasive manner in 2D and provides time-resolved, high-resolution information on impregnation processes. However, chemical information on the adsorbed metal oxide species is mostly lost during data acquisition, and therefore the technique has inherent limitations regarding the discrimination of distinct adsorbed metal oxide components. Thus, a noninvasive technique that is capable of providing detailed information regarding elemental and crystalline phase distributions over multiple dimensions would become a powerful tool in the armory of the catalyst scientist.

Synchrotron-based tomographic energy dispersive diffraction imaging (TEDDI) represents such a technique. It has been developed as a means of nondestructively exploring the structural and chemical content of individual volume elements (typically $10^{-4}-10 \mathrm{~mm}^{3}$ ) within bulk systems, such as rock, ceramics, concrete, and cementitious materials. ${ }^{[8]}$ This degree of penetration is achieved through the use of intense, hard, white X-ray beams produced by second- and thirdgeneration synchrotron wiggler devices. The volume element is defined by the intersection of the incident X-ray beam with the diffracted beam that passes through the postsample collimator into the detector. Many such volume-element locations can be visited by intelligently scanning the sample through the X-ray beam and collecting the X-ray signal from each location by means of an energy-dispersive detector. This signal contains both the diffraction pattern and fluorescence peaks from the defined volume element; therefore, a full scan gives rise to a complete diffraction and fluorescence record of the whole sample region of interest. With X-ray diffraction, 
provided at least one unique diagnostic diffraction peak can be identified for each phase, TEDDI offers a means of obtaining concentration maps for individual crystalline phases within a catalyst body in a time- and space-resolved manner.

Herein, we describe for the first time how the TEDDI technique has been employed to obtain both phase and elemental distribution information on supported metal oxides in $\mathrm{Mo} / \mathrm{Al}_{2} \mathrm{O}_{3}$ and $\mathrm{Co}-\mathrm{Mo} / \mathrm{Al}_{2} \mathrm{O}_{3}$ hydrodesulfurization catalyst bodies during the various stages of catalyst preparation. Figure 1 a shows a typical detector signal for a $\mathrm{Mo} / \mathrm{Al}_{2} \mathrm{O}_{3}$

a)
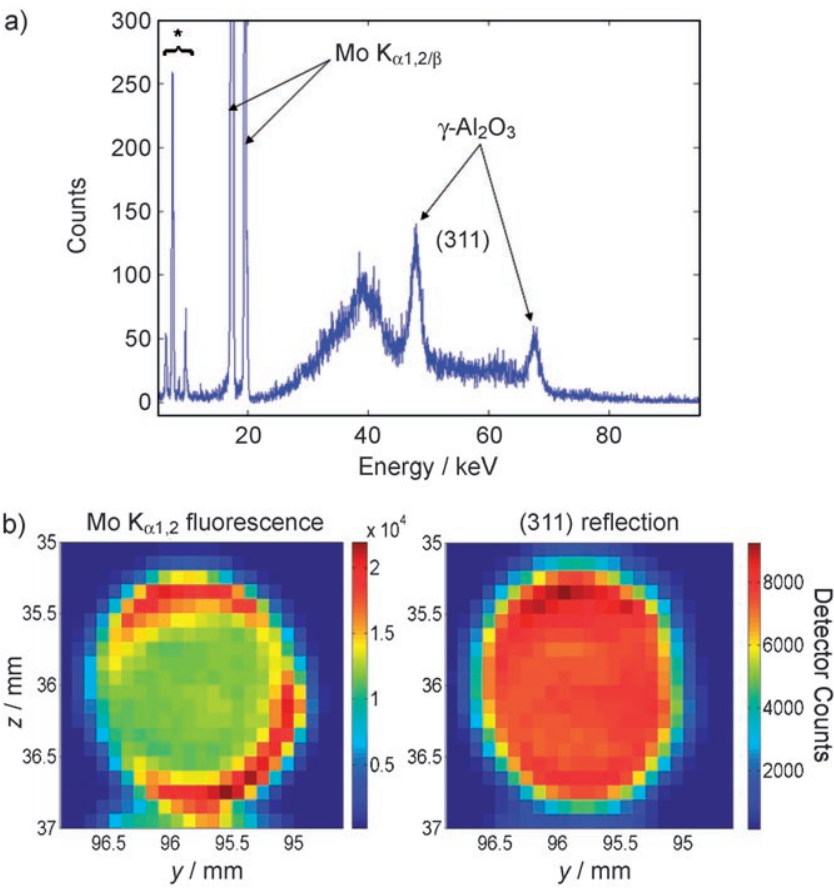

Figure 1. a) Detector signal from a $\mathrm{Mo} / \mathrm{Al}_{2} \mathrm{O}_{3}$ catalyst body after drying at $120^{\circ} \mathrm{C}$ (* represents the Ge detector escape peaks). b) A typical $y-z$ $\mathrm{Mo}_{\mathrm{Kal}, 2}$ fluorescence map (left) and a $\gamma-\mathrm{Al}_{2} \mathrm{O}_{3}$ diffraction map (right) from the same catalyst body as in (a). The red (darker) areas represent regions in which the signal and therefore the species of interest are most concentrated.

catalyst body after impregnation and drying recorded in $15 \mathrm{~s}$. A number of peaks can be identified in this pattern, which are either due to fluorescence of molybdenum (ca. 17.4 $\left(\mathrm{Mo}_{\mathrm{K} \alpha 1,2}\right)$ and $\left.19.6 \mathrm{keV}\left(\mathrm{Mo}_{\mathrm{K} \beta}\right)\right)$ or diffraction by the $\gamma-\mathrm{Al}_{2} \mathrm{O}_{3}$ phase (reflections at 67 and $78 \mathrm{keV}$ ), thus providing information on both the elemental and crystalline-phase distribution. The peaks observed at approximately 6.4, 7.5, 8.6, and 9.7 keV are artifacts from the germanium detector, known as "escape peaks" caused by the $\mathrm{Mo}_{\mathrm{K} \alpha, \beta}$ fluorescence signals.

By scanning over the whole $y-z$ area of the catalyst body, concentration maps can be obtained from the $\mathrm{Mo}_{\mathrm{Ka} 1,2}$ fluorescence and (311) $\gamma-\mathrm{Al}_{2} \mathrm{O}_{3}$ diffraction peaks. Such maps are shown in Figure $1 \mathrm{~b}$. As can be seen from the data, the dried $\mathrm{Mo} / \mathrm{Al}_{2} \mathrm{O}_{3}$ catalyst body contains no crystalline phases, aside from the support material, and has an inhomogeneous eggshell distribution of molybdenum. This result is consistent with earlier Raman microspectroscopy data, ${ }^{[9]}$ which allowed us to assign the origin of this molybdenum signal to the presence of the $\left[\mathrm{Al}(\mathrm{OH})_{6} \mathrm{Mo}_{6} \mathrm{O}_{18}\right]^{3-}$ ion. This compound is formed by reaction of the slightly acidic molybdenum solution with the aluminum support, especially if the molybdenum concentration is high and the contact time is long. At this stage, we observe that the brighter part of the corona towards the top and bottom of the sample is probably not caused by an uneven distribution of this $\left[\mathrm{Al}(\mathrm{OH})_{6} \mathrm{Mo}_{6} \mathrm{O}_{18}\right]^{3-}$ ionic complex but simply reflects a shorter path length for the escaping fluorescence signal from the sample or a sample curvature, either of which would reduce the extent of self-absorption.

Upon calcination of the $\mathrm{Mo} / \mathrm{Al}_{2} \mathrm{O}_{3}$ catalyst body at $500^{\circ} \mathrm{C}$, the $\left[\mathrm{Al}(\mathrm{OH})_{6} \mathrm{Mo}_{6} \mathrm{O}_{18}\right]^{3-}$ complex appears to break down to yield a mixture of $\mathrm{Al}_{2} \mathrm{O}_{3}$ and crystalline $\mathrm{MoO}_{3}$. This finding is illustrated in Figure 2. In addition to the Mo fluorescence and

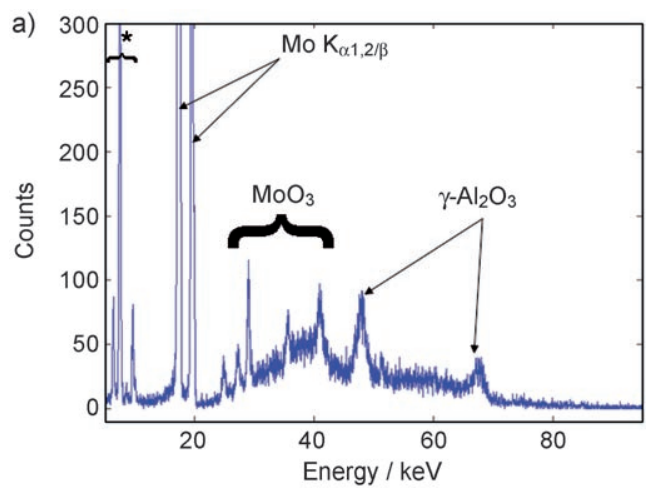

b)

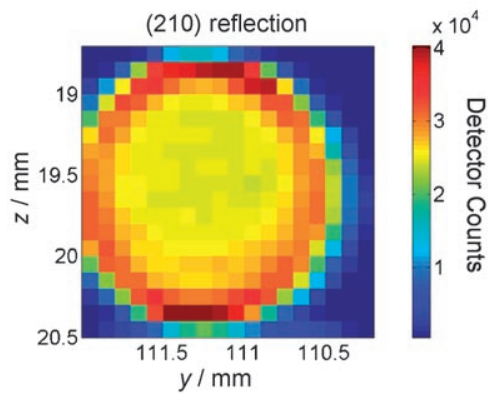

Figure 2. a) Detector signal from a $\mathrm{Mo} / \mathrm{Al}_{2} \mathrm{O}_{3}$ catalyst body after calcination at $500^{\circ} \mathrm{C}$. b) A typical $y-z$ diffraction map from the same catalyst body as in (a).

$\gamma-\mathrm{Al}_{2} \mathrm{O}_{3}$ diffraction peaks, the $\mathrm{MoO}_{3}$ crystalline phase has been monitored by measuring the diffractions at 25, 27, and $29 \mathrm{keV}$, corresponding to the (101), (400/201), and (210) reflections from $\mathrm{MoO}_{3}$, respectively. By scanning over the whole $y-z$ area of the catalyst body, a concentration map can be obtained for $\mathrm{MoO}_{3}$ from its (210) diffraction peak. From these data it can be concluded that an eggshell distribution of $\mathrm{MoO}_{3}$ is formed and that no significant redistribution occurred during the calcination step. Importantly, in hydrotreatment catalytic testing, this $\mathrm{Mo} / \mathrm{Al}_{2} \mathrm{O}_{3}$ sample displayed inferior performance because of the presence of large crystals of $\mathrm{MoO}_{3}$ on the periphery of the extrudate and the subsequent difficulty in forming active $\mathrm{MoS}_{2}$ nanoslabs from 
this material or from deeper inside the extrudate. ${ }^{[9]}$ We propose that this "eggshell" effect might be caused by either an insufficient equilibration time during the impregnation step or by the high concentration of molybdenum exceeding the dispersion limit of the support.

An important and to date unreported aspect of microspectroscopic studies of catalyst bodies is the mapping of metal oxide distribution along the additional $x-y$ and $z-x$ planes. This approach renders the tomographic TEDDI technique almost 3D, since it generates data from focal planes as opposed to fully 3D-resolved information, and it allows for a more complete characterization of the catalyst bodies. Perhaps more critically, such insight poses the question as to whether information generated in $2 \mathrm{D}$ is sufficient to understand the differences observed in catalytic behavior. Figure 3 shows a series of measurements performed in the $x-y$ plane for the calcined $\mathrm{Co}-\mathrm{Mo} / \mathrm{Al}_{2} \mathrm{O}_{3}$ catalyst body, while the

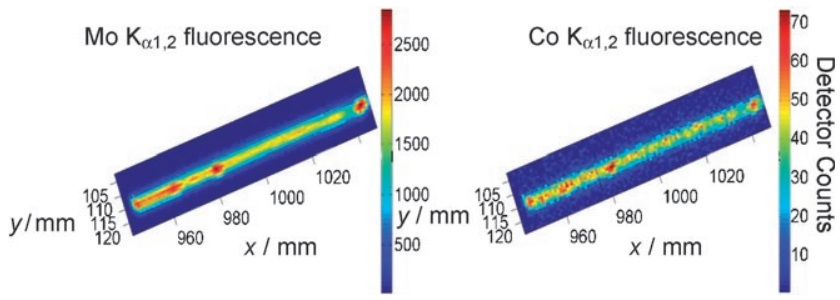

Figure 3. Concentration maps for $\mathrm{Mo}_{\mathrm{K} \alpha 1,2}$ fluorescence (left) and $\mathrm{CO}_{\mathrm{Ka} 1,2}$ fluorescence (right) in a cylindrical plane of the $\mathrm{Co}-\mathrm{Mo} / \mathrm{Al}_{2} \mathrm{O}_{3}$ catalyst body. The red (darker) areas represent regions in which the signal and therefore the species of interest are most concentrated.

accompanying $x-z$ and $z-y$ planes are given in the Supporting Information. It was found that there were no detectable amounts of crystalline cobalt or molybdenum phases present; only peaks for the $\gamma-\mathrm{Al}_{2} \mathrm{O}_{3}$ phase could be observed. This finding suggests that cobalt is contained in diffraction-silent $\mathrm{CoAl}_{2} \mathrm{O}_{4}$ and $\mathrm{CoMoO}_{4}$ phases confined in the extrudate. The $x-z$ and $y-z$ scans revealed an almost identical eggshell pattern for the Mo and Co signals, thus suggesting that their fate was intertwined. This situation, as previously proposed, is the result of the initial formation of $\left[\mathrm{Co}_{2} \mathrm{Mo}_{7} \mathrm{O}_{24}\right]^{2-}$-type anions in solution, which then anchor to the $\gamma-\mathrm{Al}_{2} \mathrm{O}_{3}$ surface through the molybdate anions during impregnation. ${ }^{[10]}$ The apparent brightness of the molybdenum signal at the righthand side of the body is caused by the differences in density affecting the self-absorption process, although in this case it is caused solely by the marked curvature of the pellet. This effect might well serve to explain the apparent density variations in the $\gamma-\mathrm{Al}_{2} \mathrm{O}_{3}$ diffraction-peak signal. However, most interestingly it can be seen from the $x-y$ scans in Figure 3 that various hot spots of Mo and Co distribution are present along the long axis of the catalyst body. These hot spots are particularly noticeable at the extremes of the body and more generally at $945-985 \mathrm{~mm}$ in the $x-y$ scan. The strong signals at the extremes of the extrudate are almost certainly due to a larger contact area with the impregnation solution, although it is currently much more difficult to explain the hot spots observed in parts of the middle. Clearly, these are not due to any density differences but reflect variations in the internal structure caused by the extrusion process, which therefore appears to have an important effect on the impregnation process.

In conclusion, we have shown that the TEDDI technique is capable of revealing $3 \mathrm{D}$ information concerning the phase and elemental distribution of metal oxide species in catalyst bodies during catalyst preparation using $\mathrm{Co}-\mathrm{Mo} / \mathrm{Al}_{2} \mathrm{O}_{3}$ hydrodesulfurization catalysts as a showcase. This first study revealed that the $2 \mathrm{D}$ information commonly obtained from space- and time-resolved spectroscopic studies may oversimplify the challenges associated with relating catalyst performance to a particular preparation method. We observe, however, that there are important additional benefits in using this approach. They include the possibility to obtain in situ data in a time-resolved manner; to identify the key steps of catalyst impregnation, drying, and calcination; and even to study, in combination with the appropriate reactor cell, a single catalyst extrudate in action. In addition, the technique can provide information on samples that are difficult or even impossible to measure with spectroscopic techniques. For example, sulfided (black) and other dark materials typically absorb strongly in the visible region of the electromagnetic spectrum, thus hampering measurements with UV/Vis microspectroscopy.

\section{Experimental Section}

Sample preparation: The cylindrical $\gamma-\mathrm{Al}_{2} \mathrm{O}_{3}$ extrudates possessed a diameter of $1.5 \mathrm{~mm}$, a length of $10 \mathrm{~mm}$, a pore volume of $0.86 \mathrm{~mL} \mathrm{~g}^{-1}$, and a surface area of $245 \mathrm{~m}^{2} \mathrm{~g}^{-1}$. The $\mathrm{Mo} / \mathrm{Al}_{2} \mathrm{O}_{3}$ sample was prepared using pore-volume impregnation with a $1.8 \mathrm{M}$ Mo $\left(\mathrm{NH}_{4}\right)_{6} \mathrm{Mo}_{7} \mathrm{O}_{24} \cdot 4 \mathrm{H}_{2} \mathrm{O}$ solution at $\mathrm{pH}$ 6.0. Drying was started $1 \mathrm{~h}$ after impregnation by passing hot air over the sample until the temperature reached $120^{\circ} \mathrm{C}$. The $\mathrm{Co}-\mathrm{Mo} / \mathrm{Al}_{2} \mathrm{O}_{3}$ sample was prepared using a $1.0 \mathrm{M} \mathrm{Mo}\left(\mathrm{NH}_{4}\right)_{6} \mathrm{Mo}_{7} \mathrm{O}_{24} \cdot 4 \mathrm{H}_{2} \mathrm{O}$ and $0.6 \mathrm{M} \mathrm{Co}\left(\mathrm{NO}_{3}\right)_{2}$ solution at $\mathrm{pH}$ 5.0. This sample was allowed to age for $15 \mathrm{~min}$ before drying. Subsequently, both samples were calcined at $500^{\circ} \mathrm{C}$ for $1 \mathrm{~h}$ in static air.

TEDDI measurements: Measurements were performed at the Daresbury SRS synchrotron station 16.4, which uses a pinhole and slit arrangement to produce a white beam and three energy-discriminating multichannel analyzer (MCA) detectors to collect the data. A schematic depiction of the setup is given in the Supporting Information. Multipoint measurements were then obtained with minimum step sizes equal to $10 \mu \mathrm{m}(x)$ and $100 \mu \mathrm{m}(y, z)$ using a 0.1 $\mathrm{mm}$ circular-cross-section beam, which gave a minimum diffracting lozenge length for the top detector of approximately $1.52 \mathrm{~mm}$.

Received: August 10, 2007

Published online: October 17, 2007

Keywords: catalyst preparation - cobalt .

heterogeneous catalysis - molybdenum - TEDDI imaging

[1] a) Catalyst Preparation: Science and Engineering (Ed.: J. Regalbuto), CRC, Boca Raton, 2007; b) Preparation of Solid Catalysts (Eds.: G. Ertl, H. Knoezinger, J. Weitkamp), Wiley-VCH, Weinheim, 1999; c) A. T. Bell, Science 2003, 299, 1688; d) A. Zecchina, E. Groppo, S. Bordiga, Chem. Eur. J. 2007, 13, 2440. 
[2] a) Hydrotreating Catalysis (Eds.: H. Topsoe, F. E. Massoth), Springer, Berlin, 1996; b) G. M. Dhar, B. N. Srinivas, M. S. Rana, M. Kumar, S. K. Maity, Catal. Today 2003, 86, 45.

[3] a) K. Bourikas, C. Kordulis, A. Lycourghiotis, Catal. Rev. Sci. Eng. 2006, 48, 363; b) W. A. Spieker, J. Liu, X. Hao, J. T. Miller, A. J. Kropf, J. R. Regalbuto, Appl. Catal. A 2003, 243, 53.

[4] A. V. Neimark, L. I. Kheifez, V. B. Fenelonov, Ind. Eng. Chem. Prod. Res. Dev. 1981, 20, 439.

[5] a) J. A. Bergwerff, T. Visser, B. R. G. Leliveld, B. D. Rossenaar, K. P. de Jong, B. M. Weckhuysen, J. Am. Chem. Soc. 2004, 126, 14548; b) J. A. Bergwerff, L. G. A. van de Water, T. Visser, P. de Peinder, B. R. G. Leliveld, K. P. de Jong, B. M. Weckhuysen, Chem. Eur. J. 2005, 11, 4591.

[6] a) L. G. A. van de Water, J. A. Bergwerff, T. A. Nijhuis, K. P. de Jong, B. M. Weckhuysen, J. Am. Chem. Soc. 2005, 127, 5024; b) L. G. A. van de Water, G. L. Beezemer, J. A. Bergwerff, M. Versluys-Helder, B. M. Weckhuysen, K. P. de Jong, J. Catal. 2006, 242, 287.

[7] a) A. A. Lysova, I. V. Koptyug, R. Z. Sagdeev, V. N. Parmon, J. A. Bergwerff, B. M. Weckhuysen, J. Am. Chem. Soc. 2005, 127,
11916; b) J. A. Bergwerff, A. A. Lysova, L. Espinosa-Alonso, I. V. Koptyug, B. M. Weckhuysen, Angew. Chem. 2007, 119, 7362; Angew. Chem. Int. Ed. 2007, 46, 7224; c) J. A. Bergwerff, A. A. Lysova, L. Espinosa-Alonso, I. V. Koptyug, B. M. Weckhuysen, Chem. Eur. J. 2007, DOI: 10.1002/chem.200700990.

[8] a) C. Hall, P. Barnes, J. K. Cockcroft, S. D. M. Jacques, A. C. Jupe, X. Turrillas, M. Hanfland, D. Hausermann, Anal. Commun. 1996, 33, 245; b) C. Hall, S. L. Colston, A. C. Jupe, S. D. M. Jacques, R. Livingston, A. O. A. Ramadan, A. W. Amde, P. Barnes, Cem. Concr. Res. 2000, 30, 491; c) D. Hausermann, P. Barnes, Phase Transitions 1992, 39, 99; d) S. D. M. Jacques, K. Pile, P. Barnes, Cryst. Growth Des. 2005, 5, 395; e) P. Barnes, A. C. Jupe, S. D. M. Jacques, S. Colston, J. K. Cockcroft, D. Hooper, M. Betson, C. Hall, S. Barè, A. R. Rennie, J. Shannahan, M. A. Carter, W. D. Hoff, M. A. Wilson, N. C. Phillipson, Nondestr. Test. Eval. 2001, 17, 143.

[9] J. A. Bergwerff, M. Jansen, B. G. Leliveld, T. Visser, K. P. de Jong, B. M. Weckhuysen, J. Catal. 2006, 243, 292.

[10] J. A. Bergwerff, T. Visser, B. M. Weckhuysen, Catal. Today 2007, DOI: 10.1016/j.cattod.2007.06.037. 